\title{
NOTE ON NAMES
}

In almost all cases, I use the English spellings of individuals' names as they used them, except in direct quotations. Mehdi Hasan's name appears in a variety of ways - "Mahdi Hassan," Mehdi Husain," and so on-but since he opted for "Mehdi Hasan" when he published his own work in English, I employ it here as well. Similarly, in his autobiography, the Nawab Server Jung used a particular spelling for his name- "Server" rather than "Sarvar" or "Sarwar"-so I follow suit. Other names are also spelled in various ways. Syed Jaffer Hussein, for instance, is also referred to as Husain and Hussain. I use the most common version and trust context will make alternate usage clear. I apply more modern spellings for some Indian towns and cities-thus Kanpur not Cawnpore, and Ambala not Umballa-but retain earlier spellings for others - thus Calcutta not Kolkata, and Bombay not Mumbai.

For readability, I refer to the couple at the center of the pamphlet scandal by their first names, Mehdi and Ellen, rather than $\mathrm{Mr}$. and Mrs. Hasan. In other cases, I use the more common convention of referring to individuals by their surnames. Many of those who were hostile to Ellen referred to her by her middle name, Gertrude, but she used "Ellen" when referring to herself; honoring the couple's practice from the time, I do the same. John Seymour Keay was always referred to as simply Seymour Keay, a practice I too follow. 
